\section{THE LIVER X RECEPTOR IS HIGHLY UPREGULATED IN MONOCYTE DERIVED MACROPHAGE AND POTENTIATES TLR-DRIVEN CYTOKINE RELEASE ACCORDING TO GENOTYPE OF -1830 T > C POLYMORPHISM}

${ }^{1} \mathrm{CH}$ Suh*, ${ }^{1} \mathrm{HA} \mathrm{Kim} *,{ }^{1}$ WY Baek*, ${ }^{1} \mathrm{JY}$ Jung ${ }^{*},{ }^{2} \mathrm{SH}$ Lee* ${ }^{*}{ }^{3} \mathrm{SS} \mathrm{Kim} * .{ }^{1}$ Ajou University School of Medicine, Rheumatology, Suwon, Republic of Korea; ${ }^{2}$ Konkouk University Medical Centre, Rheumatology, Seoul, Republic of Korea; ${ }^{3}$ Ulsan University College of Medicine, Rheumatology, Gangneung, Republic of Korea

\subsection{6/lupus-2017-000215.118}

Background and aims Liver X receptors (LXRs) are originally identified as ligand-dependent transcriptional activators and induce target genes involved in lipid metabolism. Also, LXRs have emerged as important regulators of inflammatory gene expression in several diseases. We previously reported that LXR $\alpha$ gene $(\mathrm{NR} 1 \mathrm{H} 3)$ promoter polymorphism $(-1830 \mathrm{~T}>$ C) are associated with systemic lupus erythematosus (SLE) in Koreans. Therefore, we assessed cytokine expressions according to the LXRa polymorphism in monocyte-derived macrophages from SLE patients.

Methods Macrophages were obtained after 72 hour of culture of human monocytes (U937 and THP-1) supplemented with PMA $(80 \mathrm{nM})$. Cells were transfected with $\mathrm{LXR} \alpha$ promoter constructs. Supernatants were evaluated by enzyme-linked immunosorbent assay for proinflammatory cytokines. Also, peripheral blood mononuclear cells (PBMCs)-derived macrophages from SLE patients were evaluated for proinflammatory cytokines according to genotypes of $\operatorname{LXR} \alpha-1830 \mathrm{~T}>\mathrm{C}$.

Results The expression of LXR $\alpha$ is increased in human monocyte-derived macrophages. Proinflammatory cytokines, such as IL-1 $\beta$ and TNF- $\alpha$ are decreased in expression of LXR $\alpha$. Production of proinflammatory cytokines are different according to expression of genotypes of $\mathrm{LXR} \alpha-1830 \mathrm{~T}>\mathrm{C}$. Especially, expression of LXR $\alpha$ is decreased and proinflammatory cytokines are increased in TC type of LXR $\alpha-1830 \mathrm{~T}>\mathrm{C}$ compared to TT type. These data are consistent in human PBMCderived macrophages from SLE patients according to genotypes. Increased expression of proinflammatory cytokines is related to TLR7 and TLR9 expression with LXR $\alpha$.

Conclusions These data suggest that expression of LXR $\alpha$ according to genotypes of $\mathrm{LXR} \alpha-1830 \mathrm{~T}>\mathrm{C}$ may contribute to the inflammatory response by induction of inflammatory cytokines in SLE.

\section{MATRIX METALLOPROTEINASE-9/MMP-9/GELATINASE B IN SYSTEMIC LUPUS ERYTHEMATOSUS (SLE)}

E Ugarte Berzal*, L Boon, E Martens, J Vandooren, C Benedicte, G Opdenakker. K.U.L., Immunobiology, Leuven, Belgium

\subsection{6/lupus-2017-000215.119}

Background and aims Increased levels of MMP-9 were reported in serum samples of SLE patients versus healthy controls, with the suggestion that MMP-9 plays a negative role in SLE. ${ }^{1-3}$ As a contrast, others demonstrated an inverse correlation between the levels of MMP-9 and anti-dsDNA in serum of SLE patients, ${ }^{4}$ the latter being a marker of disease severity.

The double knock-out mice model $\mathrm{B} 6^{\mathrm{pr} / \mathrm{lpr}} \mathrm{MMP}-9^{-/-}$mice shows reduced survival with extreme lymphadenopathy and splenomegaly, high lymphoproliferation, increased autoantibody $(\mathrm{a} A \mathrm{~b})$ production and pronounced autoimmune tissue injury comparing with $\mathrm{B} 6^{\operatorname{lpr} / \mathrm{pr} 5}$. These data supports our suggestion that MMP-9 plays an important role in the clearance of autoantigens $(\mathrm{aAg}) .^{5}$

Methods Our present goal is to analyse if MMP-9 plays a role in immune complex (IC) clearance.

Biochemical and molecular techniques

Results Our data suggested that MMP-9 degrades aAg, coupled to immunoglobulins in IC, but the efficiency of cleavage depends of the nature of the IC. Our preclinical data in the $\mathrm{B} 6^{\mathrm{lpr} / \mathrm{lpr}}$ lupus animal model were validated with samples from SLE patients.

Conclusions All these data may be interpreted in the way that MMP-9 acts as a protective factor in the development of the disease. Consequently, a profound study of the role of MMP9 in SLE will generate new and interesting data about pathophysiology and progression of the disease and allow us to develop new effective treatment options

\section{REFERENCES}

1. Clin Biochem 2008;41:955-9.

2. Arthritis Res Ther 2004:6:R551-6.

3. Arthritis Rheum 2004;50:858-65.

4. Mol Pathol 2003;56:244-7.

5. J Autoimmun 2011;36:239-52.

\section{A LIFE LIVED WITH LUPUS: AN INTEGRATIVE REVIEW OF THE LITERATURE}

J Wong*, C Moss, H Buttigieg. Monash University, School of Nursing and Midwifery, Melbourne, Australia

\subsection{6/lupus-2017-000215.120}

Background and aims The many manifestations of Lupus can jeopardise aspects of daily living in those with the disease. The aim of this study was to synthesise findings of primary and secondary studies that had investigated the psychosocial impacts that living with Lupus has on people.

Methods Integrative review methodology assists extraction of data from primary research and other secondary studies, to enable new or re-conceptualisation of knowledge around a topic. A systematic process of searching CINHAL, Medline and other databases resulted in 91 papers that met the inclusion and critical appraisal criteria. Findings were qualitatively coded and themed and narratively described.

Results The research revealed that people find that 'Lupus is a scary disease' and that living with the disease has 'psychosocial impacts'. Three key features of the scary disease were: 'it takes time to be diagnosed', 'living with the variations in clinical manifestations' and 'the uncertainty of where lupus may take their lives'. Living with the 'psychosocial impacts of lupus' revealed the categories: 'living with physical dysfunction and daily impediments'; 'dealing with stress, depression and anxiety' and 'impacts on personal and work relations and situations'.

Conclusions Synthesised findings about a life lived with lupus revealed the important features of 'lupus as a scary disease' and 'psychosocial impacts of lupus'. This generation of concepts informs nurses other health professionals, and is likely to assist future provision of Lupus health education and person-centred care. 